\title{
Assessment of ground-based skidding impacts on the horizontally rate and extent of soil disturbance along the margin of the skid trail
}

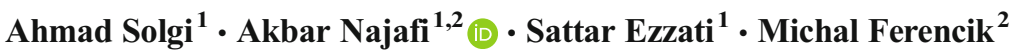

Received: 4 February 2015 /Accepted: 8 March 2016/Published online: 23 March 2016

(C) INRA and Springer-Verlag France 2016

\begin{abstract}
- Key message Skidding operations significantly influenced soil physical properties up to a 2 -m distance from the wheel ruts in a forest ecosystem. The most significant changes in soil properties were identified within a $0.5 \mathrm{~m}$ to $1 \mathrm{~m}$ transitional zone.

- Aims The main purpose of this investigation was to determine how far into a forest stand changes in soil physical properties were evident due to skidding operations.

- Methods Treatment plots with three replications included combinations of four distance zones at $0.5 \mathrm{~m}$ intervals $(0$ to $2 \mathrm{~m}$ in distance) on both sides of skid trail edges to the forest, three slope gradient levels were applied (gentle $<10 \%$,
\end{abstract}

Handling Editor: Barry Alan Gardiner

Contribution of the co-authors Ahmad Solgi: collecting data Akbar Najafi: designing the experiment, writing the paper, supervising the work, coordinating the research project

Sattar Ezatti: collecting data in the field and running the data analysis Michal Ferencik: soil sample analysis in the Lab and writing paper (Material and method)

Akbar Najafi

a.najafi@modares.ac.ir

Ahmad Solgi

Solgi_ahmad231@yahoo.com

Sattar Ezzati

s_ztt@yahoo.com

Michal Ferencik

ferencik@tuzvo.sk

1 Department of Forestry, Tarbiat Modares University, Noor, Mazandaran, Iran

2 Department of Forest Harvesting Logistic and Amelioration, Faculty of Forestry, Technical University in Zvolen, Zvolen, Slovakia moderate $10-20 \%$, steep $>20 \%$ ) and two levels of traffic intensities 20 and 40 passes (with a rubber-tyred skidder, model HSM 904). A total of 576 soil samples were used in this study.

- Results Results showed that the physical properties of soil were significantly changed by each traffic intensity in the first distance zone, where the slope was $>20 \%$ compared to soil changes at a slope of $<20 \%$. The largest changes in soil properties were identified at $0.5 \mathrm{~m}$ transitional distance zones for a slope gradient $>20 \%$ after 20 and 40 skidding cycles.

- Discussion Dry bulk density values reached its maximum levels in the first $0.5 \mathrm{~m}$ from the skid trail on slopes $>20 \%$ after 40 skidding cycles.

Keywords Adjacent disturbance $\cdot$ Hyrcanian forests $\cdot$ Skid trail edge $\cdot$ Soil disturbance $\cdot$ Skid trail slope

\section{Introduction}

Timber harvesting operations increase almost constantly in terms of their size and in the power and load capacity of logging machines (Ampoorter et al. 2007). This may lead to soil degradation in forest ecosystems, especially in mountain terrains and result in modification to the structural characteristics of the soil (Ezzati and Najafi 2010). The small contact area where the wheels of logging vehicles impact on the ground results in low traction efficiency and high ground pressures (Bygdén et al. 2004). Additionally, uneven axle loads are known to be an unsuitable option for steep slope terrains. Historically, soil disturbance on skidded areas had been relatively high, since skid roads (excavated and bladed trails) often accounted for over $20 \%$ of a clear-cut on a steep slope (Dykstra and Curran 2000). Soil disturbance from compaction can vary in intensity and spatial variability within a specific 
profile, both horizontally and vertically. Its intensity and extent are a function of the ground pressure and total load (ground pressure $\times$ contact area of the tyre or track) and soil characteristics (texture and its structure) (Håkansson and Lipiec 2000), skidding directions (Arya et al. 2014), slope of the skid trail and traffic intensity (McNabb et al. 2001; Najafi et al. 2010).

Extending soil disturbance refers to the degree of soil disturbance caused by ground skidding along the edges of the skid trail and extending into the adjoining soil. The distribution of disturbance can occur in the form of small and evenly distributed areas or, alternatively, in large areas in one or a few locations at an increasing distance from the wheel ruts. Greacen and Sands (1980) noted that a feature of compaction in the field is spatial variability, both vertically and horizontally. The pressure that a machine exerts not only influences the area located directly under its tyres; this pressure can also be horizontally distributed on the soil in the surrounding area (Horn et al. 2007). Wert and Thomas (1981) found that the transitional zones (within a 3-m band on both sides of the skid road) carried only $75 \%$ of tree volume of the undisturbed areas 32 years after logging. No detailed bulk density or chemical data were reported.

In contrast, Pennington et al. (2004) found increases in estimated standing volume in the transitional zones (within a 5-m band both sides of the snig track) in three forest stands 17-23 years after logging. Helms and Hipkin (1986) also reported $18 \%$ increases in soil dry bulk density on the areas adjacent to snig tracks compared to areas of the lowest bulk density.

Application of large shear stress due to heavy mechanized operations (Vomocil et al. 1958) in forest areas to a soil in equilibrium with an applied static load may also cause a considerable further decrease in void ratio. Raper et al. (1995) discussed that for the compaction induced by the tyres, the biggest impact in the soil was the vertical transmission of forces. Arvidsson (2003) observed that heavy axle loads during sugar beet harvesting in southern Sweden could often cause subsoil compaction, including increased penetration resistance and reduced hydraulic conductivity, which can be a long-term threat to soil productivity.

This variability tends to be common in agriculture, where mechanized operations are systematically spread across an area. However, this variability is more random within forest operations, particularly in unevenly aged stands, where mechanized forest operations are less evenly spread throughout the area. Therefore, these effects may decline with increasing distance from the wheel ruts into forests. According to Wronski (1984), side compaction caused by vehicle traffic could be attributed to the lateral movement of soil beneath the zone of maximum compression. The rotation of the tyres results in shear forces that tend to loosen the soil (Vossbrink and Horn, 2004). In soil compaction, not only pure static stress, but also dynamic forces play a role, caused by vibration of the engine, the attached implements and by wheel slip (Yavuzcan et al. 2005).

Skidding that causes soil disturbance is a challenge faced by foresters, especially in mountain forest regions. Numerous studies in the literature to date have addressed the detrimental impact of soil disturbance from a range of traffic intensity and the slope of the skid trail, both in forestry and in agriculture (McNabb 1994; Arvidsson 2003; Hamza and Anderson 2005; Ezzati and Najafi 2010; Cambi et al. 2015). However, the distribution of compaction on the margins of skid trails has, to date, received little attention. The paucity of such information has caused problems in determining the threshold spread of compaction on both sides of the skid trail. Thus, the aim of the current research is to study the horizontal impacts of skidding operations on the rate, extent and profile of soil compaction on the skid trail margins layer (up to $10 \mathrm{~cm}$ depth of soil profile) and compare it to an undisturbed area. The focus of the present study is (i) to analyse how far into the forest stands timber skidding operations have influenced soil compaction and (ii) assess these changes under varying conditions of slope and traffic intensity.

\section{Method and materials}

\subsection{Study site}

The study was conducted in a northern forest in Iran, located at $36^{\circ} 13^{\prime} \mathrm{N}$ latitude and $36^{\circ} 15^{\prime} \mathrm{N}$, and $53^{\circ} 10^{\prime} \mathrm{E}$ and $53^{\circ} 15^{\prime}$ E longitude. The study area receives $860 \mathrm{~mm}$ of precipitation annually in the form of rain at lower elevations and snow from mid-September through to May as elevation increases. The forest is composed of deciduous trees dominated by oriental beech (Fagus orientalis Lipsky) and hornbeam (Carpinus betulus). The estimated canopy cover, mean diameter (DBH) and mean height are $0.8,29.7 \mathrm{~cm}$ and $22.94 \mathrm{~m}$, respectively. Soil texture was identified in the soil laboratory to be clay loam across the trail.

\subsection{Experimental set-up}

A skid trail of $0.9 \mathrm{~km}$ in length by four metres in width, which ran downhill and roughly parallel to the slope, was selected as the study area. All timbers were transported by a rubber-tyred skidder, model HSM904; the main technical characteristics of the skidder are provided in Table 1 . An effort was made to choose a skid trail with a range of different longitudinal slope classes and any cross fall. Minimum and maximum slope gradients were 0 to $33 \%$ along the trail, respectively. A random complete block design (RCBD) was utilized to collect data about the skid trail. Twenty-four treatments were imposed on the skid trail, where the experimental variables included traffic 
Table 1 Skidding machine technical specifications

\begin{tabular}{ll}
\hline Technical specifications & HSM 904 \\
Product group power & Wheel skidder 177 HP \\
Weight $(\mathrm{Mg})$ & 8.7 \\
Number of wheels & 4 \\
Tyre dimension $(\mathrm{mm})$ & $600 / 6-30.5$
\end{tabular}

intensity for 20 and 40 skidder passes (half empty and half loaded passes), a slope in the form of gentle $(<10 \%)$, moderate $(10-20 \%)$ and steep $(>20 \%)$, as well as distance zones (four, all of which were $0.5 \mathrm{~m}$ in distance) along the same track. A schematic design of sample plot locations is shown in Fig. 1 and descriptions of each block characteristics is presented in Table 2 .

Five sample lines were delineated perpendicular to the trail in each block, $10 \mathrm{~m}$ long by $4 \mathrm{~m}$ wide, with a $2-\mathrm{m}$ buffer zone between lines to avoid interactions. Three of the five lines were then selected randomly to measure the soil physical properties. Soil samples were collected at 13 locations: between tracks (BT), left wheel (LT), right wheel (RT) and undisturbed area (control samples) at both sides; the extent of compaction was studied using eight locations at four equal distance locations ( $0.5 \mathrm{~m}$ intervals) on both margins (edge of skid trail) into the forest after 20 and 40 skidding cycles. Soil samples were taken by using $100 \mathrm{~mm}$ steel cylinders, $50 \mathrm{~mm}$ in diameter, following a perpendicular line to the axis of the skid trail (Fig. 1). A total of 36 ( 6 plots $\times 3$ lines $\times 2$ sample $)$ control samples, corresponding to sampling on each sampling line at both sides, were taken in the undisturbed area, where there was no skidding impact; this sample was taken at least $30 \mathrm{~m}$ away from the skid trail and at least one tree length from the skid road's edge in order to reduce side effects (Ezzati et al. 2011). To characterize the state of compactness of a soil layer, dry bulk density (DB), total porosity (TP), macroporosity (MP), microporosity (MIP) and void ratio (VR) were measured and compared to the undisturbed areas.

Samples from the research area were shipped to the laboratory double sealed in plastic, where they were promptly weighed and then dried in an oven at $105^{\circ} \mathrm{C}$ and reweighed to calculate dry bulk density. Soil response to applied stress was quantified according to the changes brought about in pore space. Due to variability of the size, shape and continuity of the soil samples, porosity could be a good indicator to explain changes in soil structure that one influenced by soil compaction. In this paper, total porosity was calculated based on Eq. 1 as follows:

$T P=1-\left(\frac{\mathrm{DB}}{2.65}\right) \times 100$

Where TP is total porosity (\%), DB is dry soil bulk density $\left(\mathrm{g} \mathrm{cm}^{-3}\right), 2.65\left(\mathrm{~g} \mathrm{~cm}^{-3}\right)$ is the assumed particle density according to the ASTM D854-00 2000 standard.

Macroporosity was determined using the water description method (Danielson and Sutherland 1986). In this method, soil samples were saturated in plastic tubes over a period of 5 days, the water level was slowly raised to prevent air entrapment, and weighed. The samples were then drained for $3 \mathrm{~h}$ and weighed again (Rivenshield and Bassuk 2007; Ezzati et al. 2012). We calculated the macroporosity based on Eq. 2

$$
\mathrm{MP}=\frac{w_{s}-w_{d r}}{v} \times 100
$$

Fig. 1 Illustration of sample line locations on the given block and sample point positions on the lines. Three of the five established lines were selected randomly with at least $2 \mathrm{~m}$ distance to avoid interaction

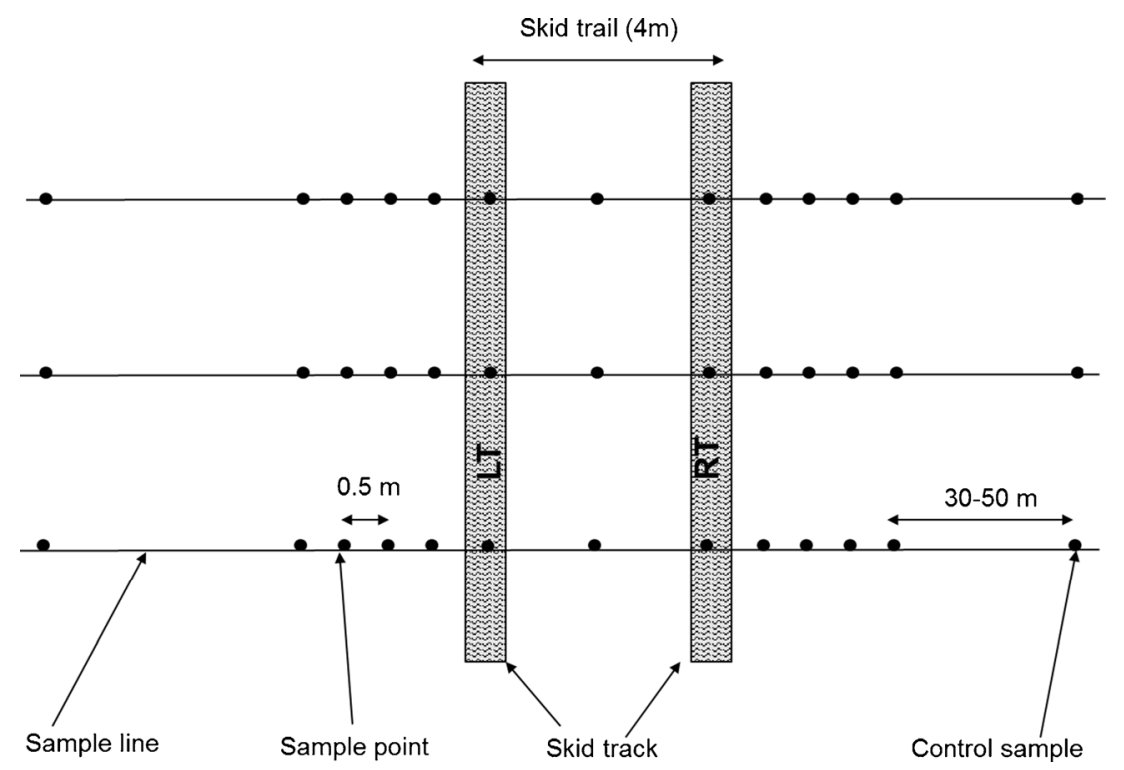


Table 2 Characteristic of sampling plot locations

\begin{tabular}{lcllll}
\hline Block no. & Gradient (\%) of block & Block order & Traffic (passes) & Length of block (m) & Elevation (m) \\
\hline 1 & 19.0 & 2 & 40 & 20.0 & 878.0 \\
2 & 6.0 & 1 & 40 & 18.0 & 886.0 \\
3 & 29.0 & 3 & 40 & 28.6 & 906.8 \\
4 & 16.0 & 2 & 20 & 34.8 & 915.7 \\
5 & 27.0 & 3 & 20 & 26.2 & 947.0 \\
6 & 9.0 & 1 & 20 & 17.8 & 971.3 \\
\hline
\end{tabular}

The plots were located at different levels of traffic and slopes on the skid trail. Three slope gradients were present for each traffic intensity segment of each skid trail: gentle slopes in which the slope gradient of the skid trail was between 0 and $10 \%$, moderate slope was between 10 and $20 \%$ and steep slopes in which the gradient exceeded $20 \%$

Where MP is macroporosity (\%), $w_{s}$ represents saturated weight $(\mathrm{g}), w_{d r}$ specifies the drained weight $(\mathrm{g})$ and $v$ refers to the volume $\left(\mathrm{cm}^{3}\right)$. Microporosity was also calculated based on Eq. 3 as follows:

MIP $=\frac{w_{d r}-w_{d}}{v} \times 100$

where $w_{d r}$ is drained weight $(\mathrm{g}), w_{d}$ is dry weight $(\mathrm{g})$ and $v$ refers to the volume $\left(\mathrm{cm}^{3}\right)$. Void ratio is the volume of voids associated with the unit of the solid and calculated according to Eq. 4 as follows:

$e=\frac{\rho_{s}}{\mathrm{DB}}-1$

where $e$ is void ratio, $\rho_{s}$ is the particle density of the soil $\left(\mathrm{g} \mathrm{cm}^{-3}\right)$ grains and DB is the measured dry bulk density $\left(\mathrm{g} \mathrm{cm}^{-3}\right)$, calculated according to Richard et al. (2001).

\subsection{Statistical analysis}

To assess the impact of traffic intensity and slope gradient levels on the horizontal compaction rate and extent of soil disturbance along the margin of the skid trail, a series of statistical analyses were made using the SPSS 11.5 statistical package (Zar 1999).

One-way and three-way ANOVA was used to assess the significance of observed differences in average bulk density, total porosity, macroporosity, microporosity and void ratio under different traffic levels, trail slopes, and extent of soil disturbance along the margin of the skid trail and to assess the significance of interaction effects. Duncan's multiple range test (significance test criterion $P \leq 0.05$ ) was used to determine the significance of differences between average bulk density, total porosity, macroporosity, microporosity and void ratio for different treatments.

\section{Results}

\subsection{Dry bulk density}

Following the removal of timber from the experimental plots, assessments were made to understand the impact of load results from timber skidding activities on the topsoil layer at the margin of the skid trail. The average changes in values of DB are shown in Table 3 for the soil's top $10 \mathrm{~cm}$ at the different transitional distance zones for both margins of the skid trail for two slope gradients after the 20th and 40th skidding cycles.

The DB values ranged from 0.92 to $0.76 \mathrm{~g} \mathrm{~cm}^{-3}$ at 0.5 and 2-m interval zones, respectively, for slopes greater than $20 \%$ after the 20th skidding cycle. With increases in both skidding pass and slope of skid trail, values of DB were increased; however, with increasing distance from the wheel ruts, these values decreased. The greatest value of DB was found in first $0.5 \mathrm{~m}$ interval zone, after 40 skidding passes on slope class $>20 \%$, and reached to $0.99 \mathrm{~g} \mathrm{~cm}^{-3}$ (Table. 3). Table 3 shows that the different load distribution patterns on the soil profile were not homogeneous with increasing distance from the wheel ruts to the adjacent forest. In general, DB values did not show any significant increase with increased distances over $0.5 \mathrm{~m}$ for gentle slope classes with two levels of traffic intensity. The results of data analyses confirmed that, regardless of the number of skidding cycles, lowest compaction occurred on the slope gradient treatments $<10 \%$ among all distance zones. The increase in DB values in the slope class $>20 \%$ for all distance zones ranged from 8.5 to $31.5 \%$ and 30 to $41.4 \%$ after 20th and 40th skidding cycles, respectively, compared to the undisturbed area (Table. 4a, b).

In Fig. 2a, b, DB values are plotted against distance zones following 20 and 40 traffic passes. In the wheel ruts, DB reached a maximum level of $1.2 \mathrm{~g} \mathrm{~cm}^{-3}$ at the soil surface; further into the forest, DB decreased sharply and tended to gradually change in comparison with what occurred in undisturbed areas. These effects were noted for both gentle and medium slope gradient classes within 
Table 3 Effect of traffic (20 and 40 passes) and slope $(0-10,10$ 20 and $>20 \%$ ) on mean values of bulk density at various distances from skid trail edge

\begin{tabular}{|c|c|c|c|c|c|c|}
\hline \multirow{3}{*}{$\begin{array}{l}\text { Passage } \\
\text { Distance zone (m) }\end{array}$} & \multicolumn{6}{|c|}{ Slope (\%) } \\
\hline & \multicolumn{2}{|l|}{$0-10$} & \multicolumn{2}{|l|}{$10-20$} & \multicolumn{2}{|l|}{$>20$} \\
\hline & 20 & 40 & 20 & 40 & 20 & 40 \\
\hline 0.5 & $0.78 \mathrm{aA}$ & $0.84 \mathrm{aA}$ & $0.92 \mathrm{bA}$ & $0.96 \mathrm{bA}$ & $0.92 \mathrm{bA}$ & $0.99 \mathrm{bA}$ \\
\hline 1.00 & $0.71 \mathrm{aA}$ & $0.79 \mathrm{aAB}$ & $0.85 \mathrm{bB}$ & $0.91 \mathrm{bA}$ & $0.95 \mathrm{cA}$ & $0.97 \mathrm{bA}$ \\
\hline 1.50 & $0.71 \mathrm{aA}$ & $0.77 \mathrm{aAB}$ & $0.82 \mathrm{bB}$ & $0.89 \mathrm{bA}$ & $0.89 \mathrm{bA}$ & $0.94 \mathrm{bA}$ \\
\hline 2.00 & $0.70 \mathrm{aA}$ & $0.72 \mathrm{aB}$ & $0.71 \mathrm{aC}$ & $0.78 \mathrm{aB}$ & $0.76 \mathrm{aB}$ & $0.91 \mathrm{bA}$ \\
\hline
\end{tabular}

Dry bulk density was measured as $0.704 \mathrm{~g} \mathrm{~cm}^{-3}$ at the control areas, values are mean and different letters within each treatment shows significant differences $(P<0.05)$

Capital case letters refer to the comparison made among four distance zones for each skidding cycle and slope class separately (column)

Lower case letters refer to the comparison made among three slope categories at each skidding cycle for the various distance zones (row) both skidding cycles (Fig. 2a, b). Soil compaction becomes harmful if the bulk density rises more than $15 \%$ compared with the control area. The portion of treatment sites showing more than $15 \%$ increase in bulk density rose dramatically with increasing slope and/or number of skidding passes.

\subsection{Total porosity}

Total porosity (TP) decreased significantly with an increase in skidding traffic and the slope of the skid trail; the largest decrease occurred after 40 cycles on steep slope treatments (Table 5). The analysis of variance for total porosity produced similar levels of significance for other sources of variation and interactions, as for the analysis of DB values (Table 5). The analyses of data with increasing distance from the wheel ruts to the margins showed that TP values increased considerably at all distance zones within both skidding cycles (Table 5). Decreases in TP values were significant up to the $1 \mathrm{~m}$ interval zone after 20 skidding cycles, while significant declines were found in these values up to the $2 \mathrm{~m}$ interval zones, compared with the undisturbed areas, after 40 skidding cycles at all slope gradient classes. Decreases in TP values after 20 and 40 skidding cycles ranged from 0.5 to $11.7 \%$ and 4.2 to $18.7 \%$, respectively, for slope gradients $>20 \%$ at all distance zones, compared to the undisturbed area

Table 4 Average changes in soil physical properties (\%) compared to undisturbed area following 20 (a) and 40 (b) skidding passes for various distance from edge of skid trail and slopes categories

(a)

Slope $(\%)$

Distance zone $(\mathrm{m}) \quad 0-10$

0.5

1.00

1.50

2.00

(b)

\section{Slope (\%)}

Distance (m)

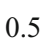

1.00

1.50

2.00
0-10

DB TP

$$
11.4-4.2
$$$$
1.4-0.9
$$$$
1.4-0.7
$$

$0.0-0.5$

10-20

$\begin{array}{ll}\text { MIP } & \text { VR } \\ 12.6 & -12.7 \\ 2.0 & -1.5 \\ 1.1 & -0.7 \\ 0.6 & 0.0\end{array}$

DB TP

$31.4-7.6$

$21.4-5.5$

$17.1-3.9$

$1.4-1.1$

$\begin{array}{lll}\text { MP } & \text { MIP } & \text { VR } \\ -28.7 & 16.4 & -22.1 \\ -14.4 & 5.7 & -14.5 \\ -11.0 & 4.27 & -11.6 \\ -1.0 & -1.4 & -2.2\end{array}$

$>20$

DB TP MP MIP VR

$\begin{array}{lllll}31.4 & -11.8 & -41.8 & 22.3 & -31.9\end{array}$

$\begin{array}{lllll}35.7 & -5.0 & -14.0 & 5.2 & -23.6\end{array}$

$\begin{array}{lllll}26.1 & -2.8 & -7.7 & 2.8 & -19.9\end{array}$

$\begin{array}{lllll}8.5 & -0.8 & -2.1 & 0.7 & -1.5\end{array}$

$$
\begin{array}{lll}
\text { DB } & \text { TP } & \text { MP } \\
20.0 & -13.4 & -58.6 \\
12.9 & -11.3 & -47.1 \\
10.0 & -5.9 & -20.2 \\
2.9 & -4.2 & -14.3
\end{array}
$$

$\begin{array}{ll}\text { MIP } & \text { VR } \\ 38.1 & -35.9 \\ 29.7 & -31.2 \\ 10.4 & -28.3 \\ 7.1 & -12.7\end{array}$

10-20

$>20$

DB TP MP MIP VR

$\begin{array}{lllll}37.1 & -17.0 & -68.7 & 40.5 & -32.3\end{array}$

$\begin{array}{lllll}30.0 & -8.9 & -44.1 & 31.2 & -35.1\end{array}$

$27.1-7.1$

$\begin{array}{lll}-17.6 & 4.9 & -27.9\end{array}$

$11.4-5.4$

$-11.8$

$1.7-10.5$

$\begin{array}{lllll}\text { DB } & \text { TP } & \text { MP } & \text { MIP } & \text { VR } \\ 41.4 & -18.7 & -76.7 & 50.2 & -39.5 \\ 38.6 & -15.4 & -62.3 & 38.1 & -37.7 \\ 34.3 & -14.5 & -54.8 & 30.6 & -34.1 \\ 30.0 & -11.5 & -43.0 & 24.4 & -30.4\end{array}$


Fig 2 a Mean \pm Std.Error of bulk density in skid trails for different slope gradient classes with different distance zones from wheel rut into the forest following 20 skidding passes. Different letters indicate statistically significant differences among different zones for each slope gradient class. b Mean \pm Std.Error of bulk density in skid trails for different slope gradient classes with different distance zones from wheel rut into the forest following 40 skidding passes. Different letters indicate statistically significant differences among different zones for each slop gradient class separately
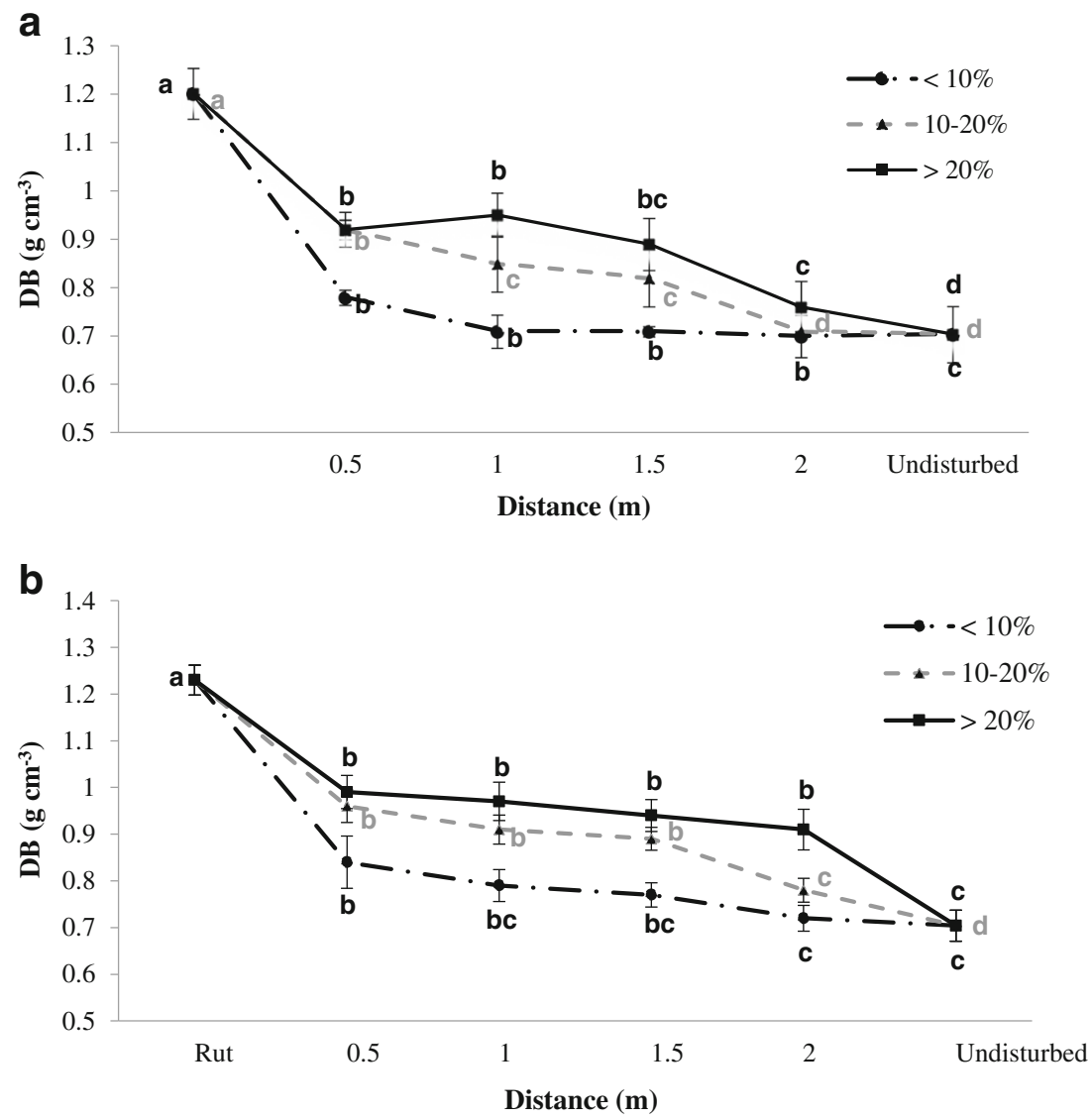

(Table 4). The differences in TP values were less than for bulk density, which most likely indicates that macroporosity was less variable than bulk density (Table 4).

\subsection{Macroporosity}

The relative quantity of coarse pores $(>50 \mu \mathrm{m})$ was significantly decreased by traffic intensity and slope gradient
(Table 6). In general, the control area had the highest amount of coarse pores. The largest effect of skidding activities on MP values occurred within the first $0.5 \mathrm{~m}$ interval to the wheel rut after 40 passes, where the slope gradient was greater than $20 \%$. The means of MP value increased with an increase in distance from the wheel ruts to the transitional zones in the uppermost layer after being subjected to traffic (Table 6). Table 4 summarizes the percentage differences in MP values
Table 5 Mean values of total porosity as influenced by traffic (20 and 40 passes) and slope ( 0 $10,10-20$ and $>20 \%$ ) at different distances from skid trail edge

\begin{tabular}{|c|c|c|c|c|c|c|}
\hline \multirow{3}{*}{$\begin{array}{l}\text { Passage } \\
\text { Distance zone (m) }\end{array}$} & \multicolumn{6}{|c|}{ Slope (\%) } \\
\hline & \multicolumn{2}{|l|}{$0-10$} & \multicolumn{2}{|l|}{ 10-20 } & \multicolumn{2}{|l|}{$>20$} \\
\hline & 20 & 40 & 20 & 40 & 20 & 40 \\
\hline 0.5 & $70.70 \mathrm{aB}$ & $68.20 \mathrm{aC}$ & $65.15 \mathrm{bC}$ & $63.92 \mathrm{bC}$ & $61.26 \mathrm{cC}$ & $60.00 \mathrm{cC}$ \\
\hline 1.00 & $73.11 \mathrm{aA}$ & $70.11 \mathrm{aB}$ & $70.12 \mathrm{bB}$ & $65.50 \mathrm{bB}$ & $67.28 \mathrm{cB}$ & $62.50 \mathrm{cB}$ \\
\hline 1.50 & $73.29 \mathrm{aA}$ & $71.00 \mathrm{aB}$ & 71.74abAB & $69.51 \mathrm{aA}$ & $68.63 \mathrm{bAB}$ & $63.11 \mathrm{bB}$ \\
\hline 2.00 & $73.44 \mathrm{aA}$ & $73.01 \mathrm{aA}$ & $73.22 \mathrm{aA}$ & $70.74 \mathrm{bA}$ & $69.85 \mathrm{bA}$ & $65.32 \mathrm{cA}$ \\
\hline
\end{tabular}

Total porosity was measured as $73.84 \%$ for the control area, values are mean and different letters within each treatment shows significant differences $(P<0.05)$

Capital case letters refer to the comparison made among four distance zones for each skidding cycle and slope class separately (column)

Lower case letters refer to the comparison made among three slope categories at each skidding cycle for the various distance zones (row) 
Table 6 Effect of traffic (20 and 40 passes) and slope $(0-10,10$ 20 and $>20 \%$ ) on soil disturbance estimated by mean values of macroporosity at various different distances

\begin{tabular}{|c|c|c|c|c|c|c|}
\hline \multirow{3}{*}{$\begin{array}{l}\text { Passage } \\
\text { Distance zone (m) }\end{array}$} & \multicolumn{6}{|l|}{ Slope (\%) } \\
\hline & \multicolumn{2}{|l|}{$0-10$} & \multicolumn{2}{|l|}{$10-20$} & \multicolumn{2}{|l|}{$>20$} \\
\hline & 20 & 40 & 20 & 40 & 20 & 40 \\
\hline 0.5 & $31.80 \mathrm{aB}$ & $28.05 \mathrm{aC}$ & $22.90 \mathrm{bD}$ & $16.27 \mathrm{bD}$ & $12.30 \mathrm{cD}$ & $9.15 \mathrm{cD}$ \\
\hline 1.00 & $37.90 \mathrm{aA}$ & $33.65 \mathrm{aB}$ & $33.80 \mathrm{bC}$ & $20.79 \mathrm{bC}$ & $22.00 \mathrm{cC}$ & $14.83 \mathrm{cC}$ \\
\hline 1.50 & $38.40 \mathrm{aA}$ & $34.99 \mathrm{aB}$ & $36.30 \mathrm{abB}$ & $31.38 \mathrm{bB}$ & $32.40 \mathrm{bB}$ & $18.02 \mathrm{cB}$ \\
\hline 2.00 & $38.70 \mathrm{aA}$ & $38.91 \mathrm{aA}$ & $38.50 \mathrm{aA}$ & $33.70 \mathrm{bA}$ & $34.70 \mathrm{bA}$ & $22.40 \mathrm{cA}$ \\
\hline
\end{tabular}

Macroporosity was measured as $39.32 \%$ for the control area. Values are mean. Different letters within each treatment shows significant differences $(P<0.05)$

Capital case letters refer to the comparison made among four distance zones for each skidding cycle and slope class separately (column)

Lower case letters refer to the comparison made among three slope categories at each skidding cycle for the various distance zones (row) among the distance treatments compared to the undisturbed state. Macroporosity was very low throughout the study area, especially on medium and steep slope gradients for the first distance interval. The MP in the first zone on a steep slope treatment following 40 skidding cycles was measured as $9.1 \%$ in the topsoil layer, which is commonly regarded as a critical level for soil aeration. Table 6 shows that a significant decrease in MP values continued up to a 2-m distance zone for a slope gradient $>20 \%$ for both skidding cycles intensities.

\subsection{Microporosity}

Changes in microporosity (MIP) values as the result of an increase in compaction were relatively minor for slope treatments $<10 \%$ from the wheel ruts into the transitional zones (Table 7). However, the biggest changes in MIP values were present for slope gradients $>20 \%$ at all distance zones following 40 skidding cycles. According to the results, when DB increased, the rate of MP significantly decreased and parallel to this, MIP volumes significantly increased (Table 4). These results were significant for slopes with a gradient $>20 \%$ and up to 1 and $2 \mathrm{~m}$ distance zones from the wheel ruts, after the 20th and 40th skidding cycles, respectively. The percentage changes in MIP values among the distance treatments compared to the undisturbed area is presented in Table 4 . The most significant changes in MIP values were by about 22.3 and $50.2 \%$, which was related to the first $0.5 \mathrm{~m}$ interval for slopes where the gradient was greater than $20 \%$ and measured for the two traffic intensities, respectively (Table 4).

\subsection{Void ratio}

Changes in the mean values of void ratio (VR) were measured as significant with an increase in traffic intensity and slope gradient on the margins of the skid trail (Table 8). The greatest reduction in mean values for VR value occurred in the first
Table 7 Mean values of microporosity influenced by traffic (20 and 40 passes) and slope $(0-10,10-20$ and $>20 \%)$ at various distances

\begin{tabular}{|c|c|c|c|c|c|c|}
\hline \multirow{3}{*}{$\begin{array}{l}\text { Passage } \\
\text { Distance zone (m) }\end{array}$} & \multicolumn{6}{|c|}{ Slope (\%) } \\
\hline & \multicolumn{2}{|l|}{$0-10$} & \multicolumn{2}{|l|}{$10-20$} & \multicolumn{2}{|l|}{$>20$} \\
\hline & 20 & 40 & 20 & 40 & 20 & 40 \\
\hline 0.5 & $38.86 \mathrm{cA}$ & $40.19 \mathrm{cA}$ & $42.22 \mathrm{bA}$ & $47.67 \mathrm{bA}$ & $48.51 \mathrm{aA}$ & $51.85 \mathrm{aA}$ \\
\hline 1.00 & $35.21 \mathrm{bB}$ & $36.48 \mathrm{cB}$ & $36.33 \mathrm{bB}$ & $44.76 \mathrm{bB}$ & $45.28 \mathrm{aB}$ & $47.68 \mathrm{aB}$ \\
\hline 1.50 & $34.90 \mathrm{aB}$ & $35.97 \mathrm{cB}$ & $35.48 \mathrm{aBC}$ & $38.11 \mathrm{bC}$ & $36.22 \mathrm{aC}$ & $45.09 \mathrm{aC}$ \\
\hline 2.00 & $34.72 \mathrm{aB}$ & $34.05 \mathrm{cC}$ & $34.7 \mathrm{aC}$ & $36.97 \mathrm{bC}$ & $35.11 \mathrm{aC}$ & $42.94 \mathrm{aD}$ \\
\hline
\end{tabular}

Microporosity was measured as $34.52 \%$ for the control area. Values are mean. Different letters within each treatment shows significant differences $(P<0.05)$

Capital case letters refer to the comparison made among four distance zones for each skidding cycle and slope class separately (column)

Lower case letters refer to the comparison made between two slope categories at each skidding cycle for the various distance zones (row) 
$0.5 \mathrm{~m}$ interval for a slope gradient $>20 \%$ following 40 skidding cycles (Table 8 ). Table 8 shows that the greatest reduction in VR was concentrated on steep slopes, rather than the gentle slopes, so that these values were significantly different up to 1.5 and $2 \mathrm{~m}$ interval zones for a slope gradient $>20 \%$ after 20 and 40 skidding passes, respectively. The lowest value of VR values was recorded in medium and steep slope gradients after 40 skidding passes (Table 4).

\section{Discussion}

\subsection{Dry bulk density}

The spatial patterns of variable traffic intensities and slope gradients were closely reflected by changes in the soil physical properties in the margin of the skid trail shortly following harvest operations. The study of the area of contact between the soil and the skidder tyres revealed that traffic intensity and slope gradient considerably influenced soil characteristics up to a distance of $2 \mathrm{~m}$ from the wheel ruts in both transitional zones.

Results showed that maximum compaction expressed as DB occurred within $1 \mathrm{~m}$ from the wheel ruts and declined with increasing distance as the total pressure was spread out over the area, compared to results from the undisturbed areas (Fig. 2a, b). This supports results published by Williamson and Neilsen (2000), Defossez and Richard (2002) and Ampoorter et al. (2007). A decrease in compaction with increasing distance from the machine footprint area can be characterized in terms of two parameters: cohesiveness, the bonding of soil particles and the angle of internal friction, which is the resistance of movement between soil particles (Greacen and Sand 1980, cited by Wood et al. 2003).

An increase in slope gradient and traffic intensity caused increased compaction up to $1.5 \mathrm{~m}$ intervals from the wheel ruts after 20 skidding cycles. This was most pronounced for slopes greater than $20 \%$, up to $2 \mathrm{~m}$ into the forest, following 40 skidding cycles. The DB values increased in terms of percentage in three slope gradients measured as gentle, medium and steep by about $11.4,31.4$ and $31.4 \%$, respectively, following 20 skidding cycles, whereas these values were 20, 37.1 and $41.4 \%$, respectively, for the first $0.5 \mathrm{~m}$ interval following 40 skidding cycles, when compared to the undisturbed areas (Table 4). The data suggested that disturbances increased in extent with an increase in slope gradient. As can be seen in Table 3, soil compaction in steep slope areas was between about two and three times greater than in the gentle slope area following 20 and 40 skidding cycles for the first $0.5 \mathrm{~m}$ interval, compared with the undisturbed areas. These findings are in accordance with the results of Najafi et al. (2010), who reported skid trail disturbance twice as high on steep slopes $(>20 \%)$ than on more gentle slopes $(<20 \%)$.

\subsection{Porosity}

The increments in DB values were translated as a decrease in soil porosity. It is likely that the increase in density took place at the expense of the macroporosity volume. One explanation for this happening with increasing soil compaction, specifically in the top layer of soil is because soil particles are rearranged and the continuity of pore spaces of both micro- and macro-pores may collapse. Decreases in macroporosity (MP) can cause poor aeration, reduce permeability to water and inhibit gaseous exchange between soil and air (Greacen and Sands 1980, Rab 1994; Ezzati et al. 2012). Additionally, an increase in DB is restricted by the MP remaining in the soil matrix at the nearest zone to the machine's footprint area after being subjected to traffic (Table 6). Under these conditions, further decreases in soil volume as a result of remaining in a steady state of compaction are not possible. This might be ascribed to residual soil air in micro-voids (Williamson and Neilsen 2000). Soil compaction

Table. 8 Mean values of void ratio in different distance zone from the edge of skid trail. Void ratio were measured following 20 and 40 passes on the plots where were established at three different slope classes.

\begin{tabular}{|c|c|c|c|c|c|c|}
\hline \multirow{3}{*}{$\begin{array}{l}\text { Passage } \\
\text { Distance zone (m) }\end{array}$} & \multicolumn{6}{|c|}{ Slope $(\%)$} \\
\hline & \multicolumn{2}{|l|}{$0-10$} & \multicolumn{2}{|l|}{$10-20$} & \multicolumn{2}{|l|}{$>20$} \\
\hline & 20 & 40 & 20 & 40 & 20 & 40 \\
\hline 0.5 & $2.41 \mathrm{cA}$ & $2.15 \mathrm{cA}$ & $1.88 \mathrm{bA}$ & $1.77 \mathrm{bA}$ & $1.87 \mathrm{aA}$ & $1.67 \mathrm{aA}$ \\
\hline 1.00 & $2.72 \mathrm{cB}$ & $2.36 \mathrm{cB}$ & $2.11 \mathrm{bB}$ & $1.90 \mathrm{bB}$ & $1.79 \mathrm{aB}$ & $1.72 \mathrm{aB}$ \\
\hline 1.50 & $2.74 \mathrm{cC}$ & $2.44 \mathrm{cC}$ & $2.21 \mathrm{bC}$ & $1.98 \mathrm{bC}$ & $1.99 \mathrm{aC}$ & $1.82 \mathrm{aC}$ \\
\hline 2.00 & $2.76 \mathrm{cC}$ & $2.70 \mathrm{cC}$ & $2.72 \mathrm{bC}$ & $2.41 \mathrm{bC}$ & $2.47 \mathrm{aC}$ & $1.92 \mathrm{aC}$ \\
\hline
\end{tabular}

Note; void ratio was measured 2.76 for the control area. Values are mean. Different letters within each treatment shows significant differences $(\mathrm{P}<0.05)$ Capital case letters refer to the comparison made among four distance zones for each skidding cycle and slope class separately (column) Lower case letters refer to the comparison made between two slope categories at each skidding cycle for the various distance zones (row) 
produced by forest vehicles significantly reduced the soil's total porosity and aeration porosity, while increasing its microporosity; this result was found for all of our treatments involving an increase in compaction stress (Tables 4 and 7). These findings are in line with the results of Startsev and McNabb (2001), who reported that during compaction, micropores may be unaffected and soil porosity changes could be confined to the mesopore space. In general, it can be noted that porosity is inversely related to bulk density and the decrease in mean porosity is likely to be a result of the increase in mean bulk density following the harvest (Rab 2004; Williamson and Neilsen 2000).

A macroporosity of at least $10 \%$ is a critical level. Any changes from normal state to a state approaching $10 \%$ is likely to have some impact on root proliferation and saturation hydraulic conductivity and in turn forest regrowth. Table 6 infers that, except for the slope $>20 \%$ within the first $0.5 \mathrm{~m}$ interval after 40 skidding cycles, all values of MP were above the critical level; thus, root proliferation and saturated hydraulic conductivity may not have been affected (Rab 2004).

The changes in MP values are only significant up to $1.5 \mathrm{~m}$ distance from wheel rut for slope gradients $>20 \%$ after 20 and 40 skidding passes. Changes in the margin soil's physical properties are to be expected in response to heavy machine traffic, due to reductions in soil volume and the closer proximity of soil particles. The net result of the closely packed soil particles and aggregates will be a loss of large-diameter soil pores, which are essential in the transmission of air and water; however, an increase will occur in small diameter capillary pores, which are necessary for water storage (Kooistra 1994). This change in porosity, reflected by increasing DB values and decreasing TP, MP and VR, is commonly observed in studies of traffic impact and soil compaction. During the passage of wheeled machines, existing voids are reduced in size and changed in shape and may become deformed, disrupted, closed or disappear completely (Kooistra 1994).

\section{Conclusion}

Although soil disturbance resulting from logging operations in different traffic intensity and slope gradient classes has been extensively studied in the last three decades, the horizontal and vertical distribution of disturbance has received less concern so far, especially in mountainous forested ecosystems. The extent and distribution of soil disturbance after skidding operations shows that pressure of harvesting vehicles can be distributed horizontally at the soil surface at least $2 \mathrm{~m}$ distance from the wheel ruts although, the current experimental design (limit of $2 \mathrm{~m}$ ) does not fully explore the extent of the impacts along the margins. Soil bulk density and macroporosity reached their maximum levels on a slope greater than $20 \%$ after 40 skidding passes. However, after the first $0.5 \mathrm{~m}$ interval zone, changes in soil properties significantly declined with an increase in distance, compared with the undisturbed areas. The information obtained in this study may be useful for managers attempting to carry out timber harvesting in an efficient manner, while still meeting environmental standards. The research can be improved by future studies on the vertical distribution of soil disturbance (subsoil) and impact of these processes on rooting of vegetation and microbial activities of soil fauna at different slope gradients, traffic intensities and skid trail directions after completing timber harvest operations in steep-slope terrains. The adverse effects of soil disturbance and in some instances the degree of disturbance can be controlled by imposing management constraints, such as limiting operations on steeply sloped areas with greater than $20 \%$ gradients, reducing tyre pressure to the minimum allowable weight, installing larger diameter tyres to increase the length of the machine footprint, and increasing the number of axles, and decreasing the number of equipment passes.

\section{References}

Ampoorter E, Goris RWM, Cornelis WM, Verheyen K (2007) Impact of mechanized logging on compaction status of sandy forest soils. For Ecol Manag 241:162-174

Arvidsson J (2003) Subsoil compaction caused by heavy sugar beet harvesters in southern Sweden. I. Soil physical properties and crop yield in six field experiments. Soil Tillage Res 60:67-78

Arya H, Rafatnia N, Najafi A, Habashi H, Gilanipour N (2014) Soil compaction rate caused by steel tracked skidder traffic in two skidding directions (Case study: Soordar Vatashan in Nour city). J For Sustain Dev 1:1-14

Bygdén G, Eliasson L, Wsterlund I (2004) Rut depth, soil compaction and rolling resistance when using bogie tracks. J Terramech 40:179-190

Cambi M, Certini G, Neri F, Marchi E (2015) The impact of heavy traffic on forest soils: a review. For Ecol Manag 338:124-138

Danielson RE, Sutherland PL (1986) Porosity. In: Klute A (ed) Methods of soil analysis, 2nd edn. Madison, American Society of Agronomy, Part 1, p 443-461

Defossez P, Richard G (2002) Models of soil compaction due to traffic and their evaluation. Soil Tillage Res 67:41-64

Dykstra PR, Curran MP (2000) Tree growth on rehabilitated skid roads in southeast British Columbia. For Ecol Manag 133:145-156

Ezzati S, Najafi A (2010) Long-term impact evaluation of ground-base skidding on residual damaged trees in the Hyrcanian forest, Iran. Int J For Res. doi:10.1155/2010/183735

Ezzati S, Najafi A, Durston T (2011) Impact of animal logging on soil physical properties in mule trail in Hyrcanian forests. Transp Res J Part-D 16:316-320

Ezzati S, Najafi A, Rab MA, Zenner EK (2012) Recovery of soil bulk density, porosity and rutting from ground skidding over a 20-year period after timber harvesting in Iran. Silva Fennca 46:521-538

Greacen EL, Sands R (1980) Compaction of forest soils. A review. Australian J Soil Res 18:163-189

Håkansson I, Lipiec J (2000) A review of the usefulness of relative bulk density values in studies of soil structure and compaction. Soil Tillage Res 53:71-85 
Hamza M, Anderson W (2005) Soil compaction in cropping systems: a review of the nature, causes and possible solutions. Soil Tillage Res $82: 121-145$

Helms JA, Hipkin C (1986) Effects of soil compaction on tree volume in a California ponderosa pine plantation. West J Appl For 1:121-124

Horn R, Vossbrink J, Peth S, Becker S (2007) Impact of modern forest vehicles on soil physical properties. For Ecol Manag 248:56-63

Kooistra MJ (1994) Effects of compaction on soil microstructure. In: Soane BD, van Ouwerkerk C (eds) Soil compaction in crop production. Elsevier, Amsterdam, pp 91-111

McNabb DH (1994) Tillage of compacted haul roads and landings in the boreal forests of Alberta, Canada. For Ecol Manag 66:179-194

McNabb DH, Startsev AD, Nguyen H (2001) Soil wetness and traffic level effects on bulk density and air-filled porosity of compacted Boreal forest soils. Soil Sci Soc Am J 65:1238-1247

Najafi A, Solgi A, Sadeghi SHR (2010) Effects of skid trail slope and ground skidding on soil disturbance. Caspiean J Environ sci 8:13-23

Pennington PI, Laffan M, Lewis R, Churchill K (2004) Impact of major snig tracks on the productivity of wet Eucalyptus oblique forest in Tasmania measured 17-23 years after harvesting. Aust For J 67:17-24

Rab MA (1994) Changes in physical properties of a soil associated with logging of Eucalyptus regnans forest in southeastern Australia. For Ecol Manag 70:215-229

Rab MA (2004) Recovery of soil physical properties from compaction and soil profile disturbance caused by logging of native forest in Victorian Central Highlands, Australia. For Ecol Manag 19:329-340

Raper RL, Bailey AC, Burt EC, Way TR, Liberati P (1995) Inflation pressure and dynamic load effects on soil deformation and soil-tyre interface. Trans Am Soc Agric Eng 38:685-689
Richard G, Cousin I, Sillon JF, Bruand A, Guérif J (2001) Effect of compaction on the porosity of a silty soil: influence on unsaturated hydraulic properties. Eur J Soil Sci 52:49-58

Rivenshield A, Bassuk NL (2007) Using organic amendments to decrease bulk density and increase macroporosity in compacted soils. J Arboricult Urban For 33:140-146

Startsev AD, McNabb DH (2001) Skidder traffic effects on water retention, pore-size distribution, and van Genuchten parameters of boreal forest soils. Soil Sci Soc Am J 65:224-231

Vomocil JA, Fountaine ILR, Reginato RJ (1958) The influence of speed and drawbar load on the compacting effect of wheeled tractors. Soil Sci Soc Am J 22:178-80

Vossbrink J, Horn R (2004) Modern forestry vehicles and their impact on soil physical properties. Eur J For Res 123:259-267

Wert S, Thomas BR (1981) Effects of skid roads on diameter, height, and volume growth in Douglas-fir. Soil Sci Soc Am J 45:629-632

Williamson JR, Neilsen WA (2000) The influence of forest site on rate and extent of soil compaction and profile disturbance of skid trails during ground-based harvesting. Can J For Res 30:1196-1205

Wood MJ, Carling PA, Mofat AJ (2003) Reduce ground disturbance during mechanized forest harvesting on sensitive forest soils in the UK. J For 76:345-361

Wronski EB (1984) Impact of tractor thinning operations on soils and tree roots in a karri forest, Western Australia. Australian. J For Res 14: 319-343

Yavuzcan HG, Matthies D, Auernhammer H (2005) Vulnerability of Bavarian silty loam soil to compaction under heavy wheel traffic: impacts of tillage method and soil water content. Soil Tillage Res 84: $200-215$

Zar JH (1999) Biostatistical analysis, 4th edition, Prentice Hall, Upper Saddle River, NJ, USA. 662 p. plus appendices 